Acta Crystallographica Section E

Structure Reports

Online

ISSN 1600-5368

\section{(2E)-3-(Biphenyl-4-yl)-1-(4-bromophenyl)- prop-2-en-1-one}

The title compound, $\mathrm{C}_{21} \mathrm{H}_{15} \mathrm{BrO}$, was obtained from 4bromoacetophenone and biphenyl-4-carbaldehyde. The geometry of the molecule is unexceptional. The compound crystallizes isostructurally with the corresponding chloro compound.

Inorganic Chemistry, School of Chemical Science and Engineering, Royal Institute of Technology (KTH), 10044 Stockholm, Sweden,

${ }^{\mathbf{b}}$ Department of Studies in Chemistry, University of Mysore, Manasagangotri, Mysore 570 006, India, ${ }^{\mathbf{c}}$ Department of Chemistry, Mangalore University, Mangalagangotri 574 199, India, and ${ }^{\mathbf{d}}$ Department of Chemistry, P. A. College of Engineering, Nadupadavu, Mangalore 574 153, India

Correspondence e-mail: afischer@kth.se

\section{Key indicators}

Single-crystal X-ray study

$T=296 \mathrm{~K}$

Mean $\sigma(\mathrm{C}-\mathrm{C})=0.016 \AA$

$R$ factor $=0.064$

$w R$ factor $=0.158$

Data-to-parameter ratio $=11.7$

For details of how these key indicators were automatically derived from the article, see http://journals.iucr.org/e.

\section{Comment}

(C) 2007 International Union of Crystallography All rights reserved
For an introduction, see Fischer et al. (2007a).

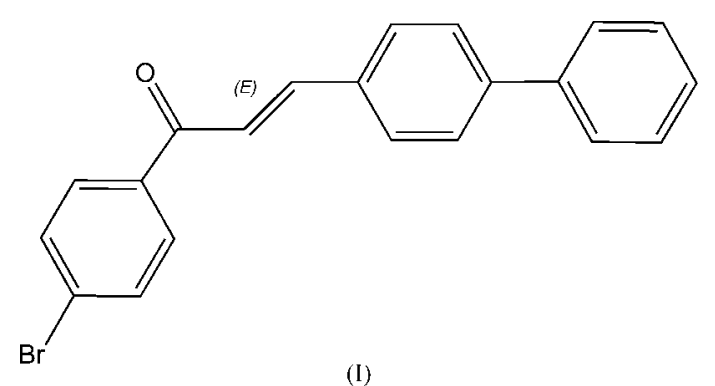

The title chalcone, (I), was prepared by treating 4-bromoacetophenone with biphenyl-4-carbaldehyde in the presence of $\mathrm{KOH}$.

Fig. 1 shows the molecular structure. The geometry of the molecule is unexceptional. The molecule deviates significantly from planarity [dihedral angles of $5.4(3)^{\circ}$ within the biphenyl group and $48.4(3)^{\circ}$ between the $\mathrm{C} 10-\mathrm{C} 15$ ring and the bromophenyl ring]. The compound is isostructural with the corresponding chloro compound (Fischer et al., 2007b).

\section{Experimental}

4-Bromoacetophenone $(1.99 \mathrm{~g}, 0.01 \mathrm{~mol})$ in methanol $(20 \mathrm{ml})$ was mixed with biphenyl-4-carbaldehyde $(1.82 \mathrm{~g}, 0.01 \mathrm{~mol})$ and the mixture was treated with a $30 \%$ potassium hydroxide solution $(3 \mathrm{ml})$ at $278 \mathrm{~K}$. The reaction mixture was then brought to room tempera-

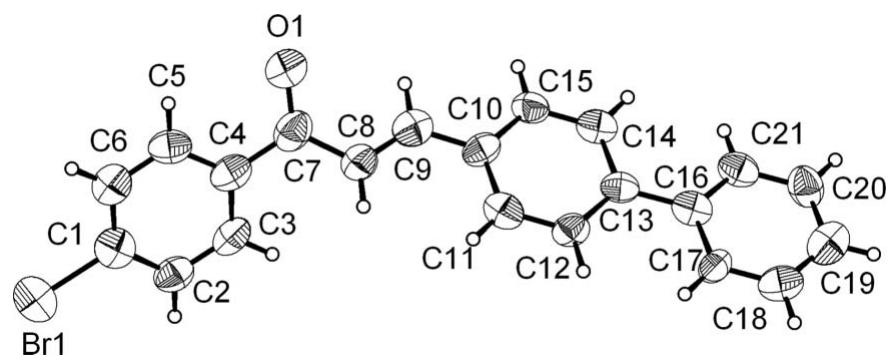

Figure 1

The molecular structure of the title compound. Displacement ellipsoids are drawn at the $50 \%$ probability level.
Received 30 January 2007 Accepted 9 February 2007 
ture and stirred for $3 \mathrm{~h}$. The precipitated solid was filtered off, washed with water, dried and recrystallized from acetone (m.p. 449-451 K). Analysis (\%) for $\mathrm{C}_{21} \mathrm{H}_{15} \mathrm{BrO}$ found (Calculated): $\mathrm{C} 69.32$ (69.44), $\mathrm{H}$ 4.10 (4.16).

\section{Crystal data}

$$
\begin{aligned}
& \mathrm{C}_{21} \mathrm{H}_{15} \mathrm{BrO} \\
& M_{r}=363.26 \\
& \text { Monoclinic, } C c \\
& a=37.35(3) \AA \\
& b=7.3663(15) \AA \\
& c=6.0978(17) \AA \\
& \beta=92.63(4)^{\circ}
\end{aligned}
$$

$$
\begin{aligned}
& V=1675.9(15) \AA^{3} \\
& Z=4 \\
& \text { Mo } K \alpha \text { radiation } \\
& \mu=2.45 \mathrm{~mm}^{-1} \\
& T=296 \mathrm{~K} \\
& 0.44 \times 0.23 \times 0.05 \mathrm{~mm}
\end{aligned}
$$

\section{Data collection}

$\begin{array}{ll}\begin{array}{l}\text { Bruker-Nonius KappaCCD } \\ \text { diffractometer }\end{array} & 4893 \text { measured reflections } \\ \text { Absorption correction: numerical } & 2434 \text { independent reflections } \\ \quad \text { (Herrendorf \& Bärnighausen, } & 1640 \text { reflections with } I>2 \sigma(I) \\ \text { 1997) } & R_{\text {int }}=0.075 \\ T_{\min }=0.530, T_{\max }=0.864 & \\ \text { Refinement } & \\ R\left[F^{2}>2 \sigma\left(F^{2}\right)\right]=0.064 & \\ w R\left(F^{2}\right)=0.158 & \Delta \rho_{\max }=0.24{\mathrm{e} \AA^{-3}}^{-3} \\ S=1.17 & \Delta \rho_{\min }=-0.34 \mathrm{e}^{-3} \\ 2434 \text { reflections } & \text { Absolute structure: Flack (1983), } \\ 208 \text { parameters } & 924 \text { Friedel pairs } \\ \text { H-atom parameters constrained } & \text { Flack parameter: }-0.01(3)\end{array}$

$\mathrm{H}$ atoms were placed at calculated positions and refined as riding on the respective carrier atom, with $\mathrm{C}-\mathrm{H}=0.93 \AA$ and $U_{\text {iso }}(\mathrm{H})=$ $1.2 U_{\text {eq }}(\mathrm{C})$. The structure appears to exhibit turbostratic disorder, which could be detected in precession photographs that were simu- lated from the CCD data. The disorder was accounted for in the data processing with EVALCCD (Duisenberg et al., 2003).

Data collection: COLLECT (Nonius, 1999); cell refinement: $D I R A X / L S Q$ (Duisenberg, 1992); data reduction: EVALCCD (Duisenberg et al., 2003); program(s) used to solve structure: SHELXS97 (Sheldrick, 1997); program(s) used to refine structure: SHELXL97 (Sheldrick, 1997); molecular graphics: DIAMOND (Brandenburg, 2006); software used to prepare material for publication: publCIF (Westrip, 2007).

One of the authors (BKS) thanks AICTE, Government of India, for financial assistance through the Career Award for Young Teacher's Scheme, and BVA thanks Mangalore University for permission to carry out the research work. The Swedish Research Council (VR) is acknowledged for providing funding for the single-crystal diffractometer.

\section{References}

Brandenburg, K. (2006). DIAMOND. Release 3.1d. Crystal Impact GbR, Bonn, Germany.

Duisenberg, A. J. M. (1992). J. Appl. Cryst. 25, 92-96.

Duisenberg, A. J. M., Kroon-Batenburg, L. M. J. \& Schreurs, A. M. M. (2003). J. Appl. Cryst. 36, 220-229.

Fischer, A., Yathirajan, H. S., Ashalatha, B. V., Narayana, B. \& Sarojini, B. K. (2007b). Acta Cryst. E63, o1353-o1354.

Fischer, A., Yathirajan, H. S., Ashalatha, B. V., Narayana, B. \& Sarojini, B. K. (2007a). Acta Cryst. E63, o1349-o1350.

Flack, H. D. (1983). Acta Cryst. A39, 876-881.

Herrendorf, W. \& Bärnighausen, H. (1997). HABITUS. University of Karlsruhe, Germany.

Nonius (1999). COLLECT. Nonius BV, Delft, The Netherlands.

Sheldrick, G. M. (1997). SHELXL97. University of Göttingen, Germany. Westrip, S. P. (2007). publCIF. In preparation. 